INTERNATIONAL JOURNAL OF MULTIDISCIPLINARY RESEARCH AND ANALYSis

ISSN(print): 2643-9840, ISSN(online): 2643-9875

Volume 03 Issue 12 December 2020

DOI: 10.47191/ijmra/v3-i12-01, Impact Factor: 5.522

Page No.- $260-268$

\title{
Development of a Diversity Panel for Traditional Rice (Oryza Sativa L.) Accessions/Varieties in Sri Lanka
}

\author{
S. Somaratne ${ }^{1}$, S. R. Weerakoon ${ }^{2}$ \\ ${ }^{1,2}$ Department of Botany, the Open University of Sri Lanka, Nawala, Nugegoda, Sri Lanka
}

\begin{abstract}
Oryza sativa L. varieties grown in Sri Lanka from ancient times to the middle of the last century are known as traditional rice varieties and a collection of over 2000 traditional rice accessions conserved at Gene Bank, Plant Genetics Resource Center (PGRC), Peradeniya, Sri Lanka. Farmers preferred traditional rice varieties for their adaptability to biotic and abiotic stresses and are an important component of the biodiversity of Sri Lanka. A detailed understanding of the genetic structure and diversity of traditional rice varieties is essential for the effective utilization of rice genetic resources and identification of potential parents possessing valuable genetic traits for future crop improvement in rice breeding programmes. The objective of the present study was phenotypic and molecular characterization of one hundred (100) traditional rice accession/varieties collected from PGRC, Sri Lanka and identification of a broad diversity panel for these traditional rice accessions/varieties. Rice varieties were grown in a plant house following Randomized Complete Block design with 4 replicates and 5 plants per each replicate. Thirty-two (32) agro-morphological characters were observed. Green leaves of rice varieties were individually collected from 20 day-old seedlings for gDNA extraction using Plant genomic DNA kit followed by the CTAB protocol. Thirty-three microsatellite (Simple Sequence Repeat - SSR) primer pairs were used to assay genetic variation. DNA amplification was carried out using a thermal cycler and PCR products were subjected to fragment analysis by capillary
\end{abstract} electrophoresis.

Descriptive statistics and basic inferential statistical analyses were performed to access the variation of agro-morphological characters among rice varieties. Data were subjected to cluster analysis (CA) to examine the grouping tendencies and supplemented with Multidimensional scaling (MDS) to explore the procedural differences in the outcome. CA and MDS produced seven (07) groups which were further analyzed using Classification and Regression Analysis (CART) to extract the diagnostic agro-morphological features. Based on CART result, groups of rice varieties were characterized by lemma-palea color, presence or absence of awn, seedling height, and flag-leaf angle. Traditional rice accessions/varieties represent distant clusters on agro-morphological features.

Molecular analyses revealed, all 33 loci displayed polymorphism (66.7-96.9 \%) among 100 traditional rice accessions/varieties with a total of 387 alleles identified with an average of 11.72 alleles per accession. AMOVA results showed that $34 \%$ of the variation distributed among accessions/varieties, $59 \%$ of among individuals and $7 \%$ within individual indicating a comparatively high level of genetic differentiation among individuals of selected rice accessions/varieties. Structure analysis results illustrated that all 100 accessions/varieties were genetically structured into fifteen well-separated groups, high $\Delta K$ peak was recorded at $\mathrm{K}=15, \mathrm{~K}=5, \mathrm{~K}=19$ and $\mathrm{K}=2$ respectively. UPGMA analysis based on Jaccard's similarity separated the accessions into five (5) major clusters. A cophenetic correlation with $r=0.786$ strongly supported the clustering pattern of UPGMA dendrogram. A principal coordinate analysis (PCOA) also confirmed the UPGMA clusters.

The genetic diversity information obtained will be useful in efficient use of Sri Lankan rice germplasm collection in breeding programmes. This information will also be useful in management of in situ and ex situ germplasm collections in conservation programs for traditional rice varieties.

KEYWORDS: Agro-morphological characterization, Molecular characterization, Diversity panel, Oryza sativa L., Traditional rice accessions/varieties 


\section{Development of a Diversity Panel for Traditional Rice (Oryza Sativa L.) Accessions/Varieties in Sri Lanka}

\section{INTRODUCTION}

A comprehensive knowledge on genetic diversity and population structure of germplasm collections is important for crop improvement. Rice (Oryza sativa L.) is the staple food in Sri Lanka, cultivated as a wetland crop in all the districts of the island. According to Department of Agriculture of Sri Lanka reports, rice is the single most important crop occupying $34 \%$ percent (0.77 /million ha) of the total cultivated area in the island. Rice provides $45 \%$ total calorie and $40 \%$ total protein requirement of an average Sri Lankan (Crop recommendations, 2014). Approximately 75\% of the rice lands in Sri Lanka are located within the inland valley systems with varying form and size, and the balance $25 \%$ is in coastal plains and associated flood plains (Panabokke, 1996). Out of total cultivated amount, around 99\% of the area is cultivated with new improved rice varieties. The remaining area is cultivated with traditional rice varieties with low yield. Although new improved varieties produce comparatively higher yields, local and export market demand for traditional rice varieties is higher for their grain qualities, such as high fiber content, despite the lower production (Wickramasinghe and Noda, 2008). Moreover, farmer's perceptions (Efisueet al., 2008), improvement of system sustainability (Abeyratne, 1956) and the higher adaptability to problem soils (Mandal et al., 1999) further increased interest towards traditional rice varieties.

The overall population structure of global rice germplasm has been well characterized. However, detailed analyses on countryspecific basis have only been recently begun (Thomson et al., 2007). The extent of genetic variability exists in a gene pool is an important factor for genetic improvement in rice. Sri Lanka's rice gene pool consists of many abiotic and biotic stress tolerant traits with diverse agronomical characters (Ranawake and Amarasinghe, 2014).

Oryza sativa varieties which have been grown in Sri Lanka from ancient time to the middle of the last century are known as traditional rice varieties. A landrace is a dynamic population(s) of a cultivated plant that has historical origin, distinct identity and lacks formal crop improvement, as well as often being genetically diverse, locally adapted and associated with traditional farming systems (Camacho Villa et al., 2005; Choudhury et al., 2013).Sri Lanka is considered as one of the secondary diversity centers for rice genetic resources (Kobayashi et al., 1991). In ancient times, farmers cultivated traditional rice varieties, due to their adaptability to Sri Lankan soil types, climate, geography, and harsh environmental conditions such as flood, drought, soil salinity, iron toxicity, pests, and diseases. The traditional rice varieties have a historical origin, distinct identity and lack formal crop improvement, as well as often being genetically diverse, locally adapted and associated with traditional farming systems (Camacho Villa et al., 2005).

A long history of traditional rice production across diverse environments in Sri Lanka has led to a diverse array of traditional rice varieties. However, the relative importance and influence of yield related traits on grain yield have changed over time due to rice improvement. The yield potential of a rice variety is a theoretical concept determined by a complex series of interactions with the components of the environment it is exposed to. Although recommendations of crop varieties are done based on grain yield, there are other important traits related to grain quality and/or agronomy which are not related to grain yield (Samitaet al., 2005). Under such circumstances, selection based on yield can lead to the loss of these important characters. Therefore, classification using multiple morphological characteristics is important to identify adaptation of a variety and to improve the evaluation of varieties for potential adaptation (Lin and Binns, 1985; Lin et al., 1986). At present, there is still a lack of information on morphological diversity, how the diversity has changed with rice improvement and its impact on grain yield of traditional and improved rice varieties in Sri Lanka.

Traditional rice varieties represent important genetic reservoirs with valuable traits and there is an urgent need to provide proper incentives and encourage the farmers to cultivate these to help in the in situ conservation of this important gene pool. The selected rice cultivars with abiotic stress tolerance have the potential for direct introduction as cultivars or utilization in the breeding programs. Sri Lankan traditional rice varieties were found to be biotic and a biotic stress tolerant showing exceptional levels of tolerance which play an important role in rice breeding programs (Madurangiet al., 2012; Munasingheet al., 2017).

However, these varieties are rapidly being lost due to favor of agronomically improved rice varieties. Gene Bank of Plant Genetics Resource Center (PGRC) conserves a collection of over 2000 traditional rice accessions/varieties. Only a few studies have so far been conducted on genetic differentiation among Sri Lankan traditional rice (Rajkumar et al., 2011; Ranawake and Amarasinghe, 2014) and there is a need to conduct a comprehensive study.

Rice varietal improvement by incorporating germplasm from traditional rice may lead to important advances as these varieties seem to harbor significantly higher genetic and phenotypic diversity than the cultivated rice (Bentota and Weerasinghe, 2005; Atwell, et al., 2014). Moreover, traditional rice varieties are one important component of the biodiversity of Sri Lanka.

Genetic fingerprinting of these cultivars is essential to distinguish them and to characterise accessions/varieties.Molecular markers such as simple sequence repeats (SSR) and microsatellites are useful for assessing genetic variations within conserved gene pool in rice. To date, more than two thousand SSR markers of cultivated rice are available and these provide a powerful tool for studying close relatives. SSRs are simple, tandemly repeated, nucleotide sequence motifs flanked by unique sequences 


\section{Development of a Diversity Panel for Traditional Rice (Oryza Sativa L.) Accessions/Varieties in Sri Lanka}

(Roa et al. 2000) and have become useful markers for genetic diversity analyses because they detect high levels of allelic diversity, occur frequently throughout plant genomes, and are easily assayed by PCR. SSR markers have been extensively used to identify genetic variation among rice species to analyze genetic structure within cultivated rice (Ren et al. 2005), and to evaluate genetic diversity among strains of wild rice (Shishido et al. 2006) and among cultivars of cultivated rice (Yu et al. 2003). Further, microsatellites have been used for studies of parentage (Roa et al. 2000), genetic mapping and breeding, gene flow, genetic diversity and population differentiation (Cho et al. 2000).Genetic differentiation among selected 46 Sri Lankan traditional rice (Oryza sativa ) varieties and wild rice species were conducted using AFLP markers by Rajkumar et al., (2011).

Therefore, despite of limited studies conducted, there is still a strong need for more detailed characterization of the responses and acclimatization mechanisms of rice under stresses that is occurring in farmers' fields. Thus, integration of crop agromorphology and molecular approaches to dissect complex environment tolerance traits is essential. The objectives of the present study are; phenotypic characterization of traditional rice accessions/varieties collected from PGRC, Sri Lanka, Molecular analysis of traditional rice accession/varieties, and identification of a broad diversity panel (core collection) of traditional rice accessions/varieties.

\section{METHODOLOGY}

Collection of seed material

One hundred (100) Sri Lankan traditional rice accessions/varieties collected from PGRC, Sri Lanka were used in the study.

\section{GERMINATION OF SEEDS}

Seeds were kept at $50^{\circ} \mathrm{C}$ for 5 days to break the dormancy. Then seeds were kept in $70 \%$ alcohol for 2 minutes and washed properly with distilled water and dipped in $2 \%$ Clorox for about 30 minutes and again washed properly with distilled water. Then seeds were kept in an incubator at $35^{\circ} \mathrm{C}$ for 7 days under dark condition. The experiment was conducted at seedling stage. Germinated seeds were planted in plastic trays filled with soil collected from paddy fields.

\section{AGRO-MORPHOLOGICAL CHARACTERIZATION}

The study was carried out in a plant house at The Open University of Sri Lanka, Nawala in the Low country Wet Zone, Western Province of Sri Lanka. The average ambient temperature was $28-32^{\circ} \mathrm{C}$ and average relative humidity was $80-85 \%$ in the experiment site during the experiment period. The soil was collected from paddy field and filled into pots ( $5 \mathrm{Kg} / \mathrm{pot}$ ).

The germinated seeds were allowed for 2 weeks for reaching the seedling stage and were planted in pots according to Randomized Complete Block design with 4 replicates and 5 plants per each replicate. Fertilizer management and the other crop management practices were followed according to the recommendations of Department of Agriculture. Thirty-two (32) agromorphological characters were observed/collected as explained in PGRC Characterization Catalogue on Rice Germplasm (1999).

\section{STATISTICAL ANALYSES}

Data collected on agro-morphological characters of traditional rice accessions/varieties were analyzed using different statistical procedures. Prior to the analysis, data was converted to unique type i.e. Nominal data. Descriptive statistics included frequency analysis, and cross tabulation. Inferential statistical analyses were carried out using $\chi^{2}$ test and multivariate analytical techniques such as cluster analysis (CA) and Multidimensional scaling (MDS) to explore the statistical procedural variations in the outcomes. These procedures were used to examine the patterns of grouping of traditional rice accessions/varieties according to their agro-morphological features. Based on the grouping patterns reflected in the analyses, rice varieties were grouped into seven (07) categories such as A, B, C, D, E, F and G (Table 1). In addition, classification and regression analysis was performed to extract the diagnostic agro-morphological features of the groups of traditional rice accessions/varieties include in the study.

Table 1: Groups of traditional rice accessions/varieties resulted from the CA, PCA and MDS on agro-morphological data

\begin{tabular}{|l|l|}
\hline $\begin{array}{l}\text { Group and Number } \\
\text { of rice varieties }\end{array}$ & Rice variety (Accession No.) \\
\hline
\end{tabular}




\section{Development of a Diversity Panel for Traditional Rice (Oryza Sativa L.) Accessions/Varieties in Sri Lanka}

\begin{tabular}{|c|c|}
\hline A (33) & $\begin{array}{l}\text { Murungabala wee (3246), Kanni murunga (3260), Periavellai (3279), Suduru samba (3333), Vanam } \\
\text { (3488), Pokuru wee (3499), Maha ma wee (3551), Polon wee (3553), Muthu samba (3564), Pokkali } \\
\text { (3573), El wee (3578), Seedevi (3605), Lumbini (3613), Maha wee (3618), Gal pa wee (3341), Kiri } \\
\text { naran (3350), Kalundai (3381), Eth samba (3383), Moddaikaruppan (3388) Wannidahanala(2053), } \\
\text { Hattapasdawas wee (2051), Dahanala (2049), Herath (2048), Bala samba (2047), Herathbanda } \\
\text { (2063), Handiran (2057), Gonabaru (2056), Dingirimenika (2055), Demas (2054), Wedaheenati } \\
\text { (2340), Hal sudu wee (2110), Dik wee (2109) Heendik wee (3191) }\end{array}$ \\
\hline$B(03)$ & Kalu heenati(3471), Pihatu wee (3403), Kurulu wee (4903) \\
\hline C (02) & Kattagarang(3176), Rathuheenati(3390) \\
\hline $\mathrm{D}(02)$ & GaluSulai(4616),Thirissa(3186) \\
\hline$E(02)$ & Kaluhondarawalu(4622) and Yalalu(4606) \\
\hline$F(27)$ & $\begin{array}{l}\text { Moothuki El (3180), Kuruhondarawalu(3184), Gangala(3185), Khombila(3188), Wanduru wee } \\
\text { (2046), Balamurungakayan (2045), Batapola wee (2036), Madayal (3475), Rankiri(3476), Sudugoda } \\
\text { wee (3477), Japan sulai (3393), Devereddiri (3398), Atta wee (02035), Wanniheenati(3401), } \\
\text { Batapola El (2038), Magoda El (4905), Nara wee (4908), Niyan wee (4909), Pathmawee(4912), } \\
\text { Sudugalkada(3983), Welihandiran (3916), Mahamenik(3923), Manikkam(3901), Rath El (3705), } \\
\text { Gambada Samba (3714), Godaheenati (3724), Kuruluthuda(4553), }\end{array}$ \\
\hline G (31) & $\begin{array}{l}\text { Soothuru wee (3179), HathiEl (3183), Molligoda(4770), kurulu wee (4541), MadaEl (3177), } \\
\text { Yalihanthiran (3187), Pushmaraga (3979), Andikulan (3189), Mahakuru wee (3190), Puwakmalata } \\
\text { samba (3486), Gires (3193), Katharamana(3194), Bala Murunga (2108), Hetada (2069), Heen } \\
\text { murunga (2979), Mas samba (2349), Duru wee (2990), Polayal (3071), Thanthiri Balan (3072), } \\
\text { Ratnawalu (4916), Wedaheenati (4917) Pachchaperumal (5383), Black gora (5387), Malawariya } \\
\text { (5527), Gallkatta (3195), Nanduheenati (3197), Arnolis wee (3198), Rathkuda (3231), Ralukuda } \\
\text { (3232), Rathawalu (3233), Liyanweli (4904) }\end{array}$ \\
\hline
\end{tabular}

\section{MOLECULAR CHARACTERIZATION}

A total of 100 traditional rice accessions/varieties collected from PGRC, Gannoruwa were used in the study. The green leaves were individually collected from 20 day-old seedlings for DNA extraction. The gDNA was extracted using the Plant genomic DNA kit (Biomed DL114-01) following by the CTAB protocol. Thirty-three microsatellite (Simple Sequence Repeat - SSR) primer pairs were used to assay genetic variation. The DNA amplification was carried out using a 2,720-thermal cycler (Applied Bio systems). PCR products were subjected to fragment analysis by capillary electrophoresis using an Applied Bio systems 3130xI DNA analyzer (Applied Bio systems).

\section{RESULTS AND DISCUSSION}

\section{Agro-Morphological Characterization}

Descriptive statistics indicated that variation of agro-morphological characters across rice varieties are negligible and certain characters such as presence/absence of awn, characteristics of awn are restricted to certain rice varieties.

However, result of the Kruskal-Wallis test showed that most of the agro-morphological characters significantly vary across rice varieties $(p<0.05)$. However, the variation of stem color among the rice varieties was not statistically significant $(p>0.05)$.

The result of CA and MDS indicated that majority of rice varieties are clustered into seven (07) groups in the dendrogram (Figure 1) and biplot of MDS dimensions and certain rice varieties indicated a grouping tendency. It is clear from the MDS biplot that the verities included in the study grouped into seven categories.

The characterization of these categories was confirmed by the results of CART (Classification and Regression Tree Analysis) analysis (Figure 2). According to the results of CART analysis, traditional rice varieties which consist of seven groups can be characterized by the characters; lemma-palea color, presence or absence of awn, seedling height, and flag leaf angle (Table 2).

Table 2: Characterization of groups of traditional rice varieties. Height class $1=<20 \mathrm{~cm}, 2=>=20,3=<25 \mathrm{~cm}$ and $4=>=25 \mathrm{~cm}$

\begin{tabular}{|c|c|c|c|c|}
\hline Rice group & Flag leaf angle & Awning & $\begin{array}{c}\text { Lemma-palea } \\
\text { color }\end{array}$ & $\begin{array}{c}\text { Seedling height } \\
\text { (Height class) }\end{array}$ \\
\hline $\mathrm{A}$ & 2 & 4 & 3 & 2 \\
\hline
\end{tabular}


Development of a Diversity Panel for Traditional Rice (Oryza Sativa L.) Accessions/Varieties in Sri Lanka

\begin{tabular}{|c|c|c|c|c|}
\hline B & 1 & Absent & 9 & 2 \\
\hline C & 2 & 4 & 3 & 3 \\
\hline D & 4 & 4 & 7 & 3 \\
\hline E & 1 & 6 & 3 & 2 \\
\hline F & 2 & 6 & 2 & 3 \\
\hline G & 4 & 4 & 2 & 3 \\
\hline
\end{tabular}

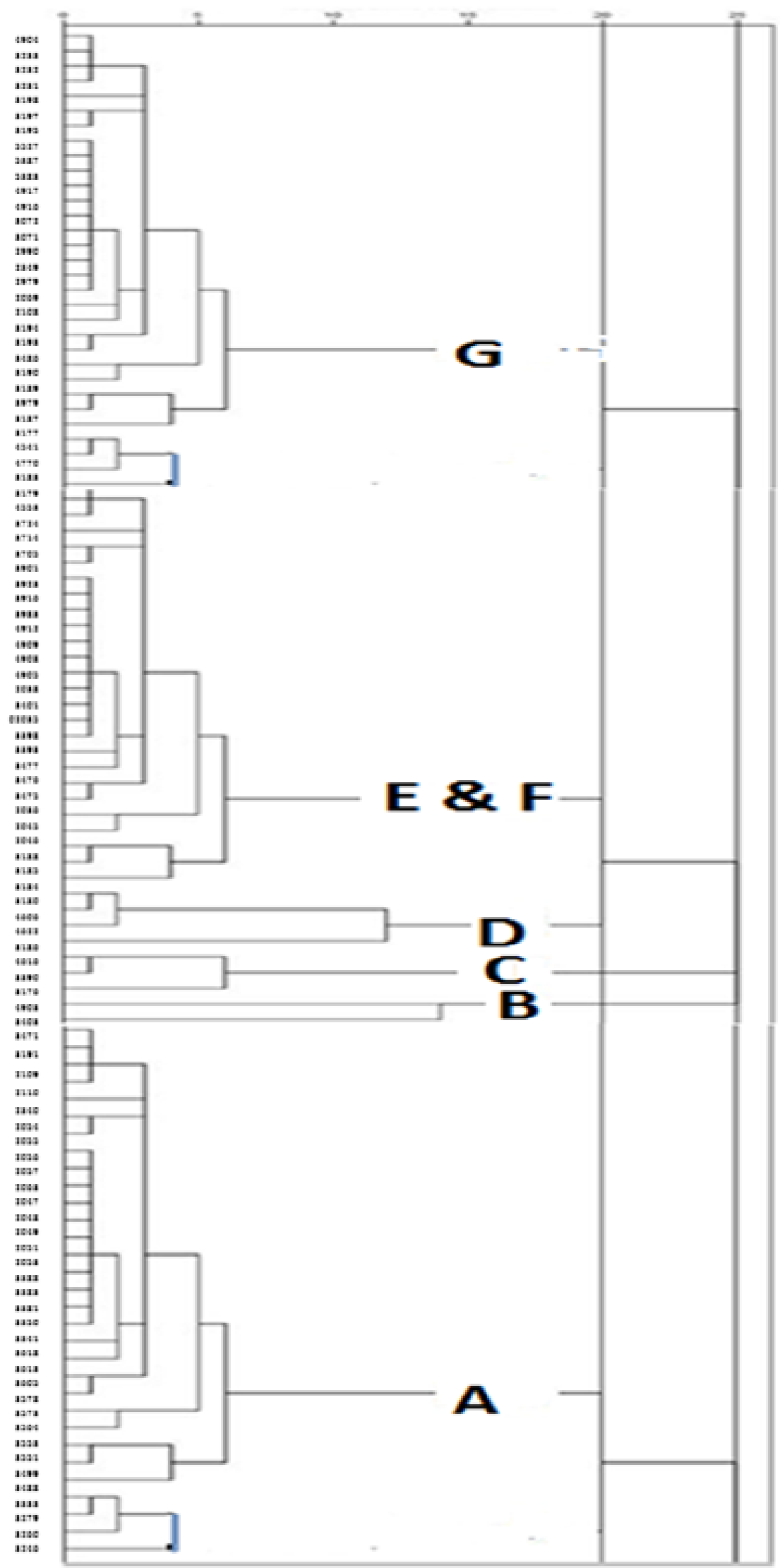


Figure 1: Dendrogram resulted from the agro-morphological characters of 100 traditional rice accessions/varieties

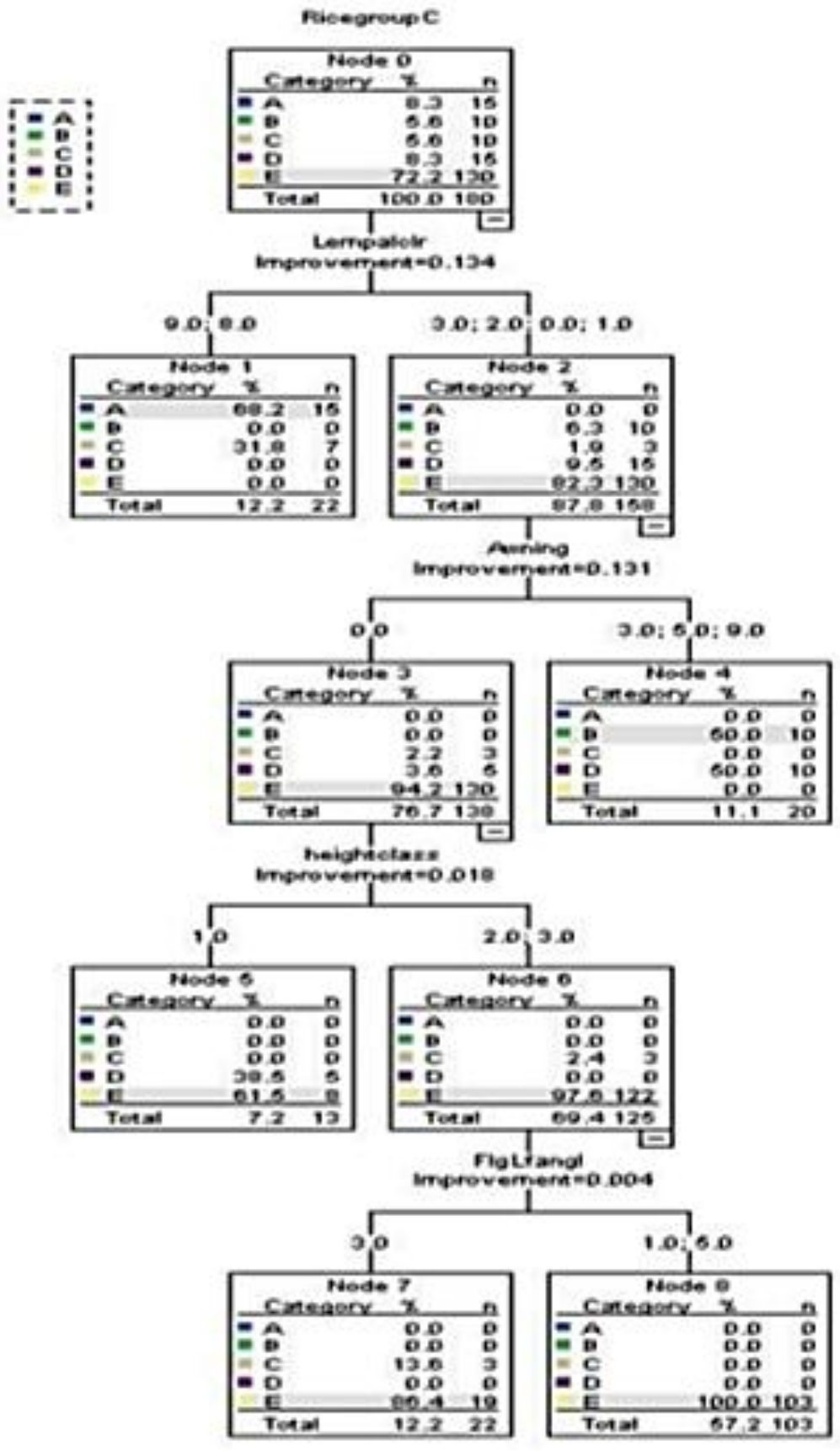

Figure 2: Summary of the characterization of the groups of rice accessions/varieties resulted from the CA and MDS Analysis using CART analysis

\section{Molecular Characterization}

According to the present study, all 33 loci displayed polymorphism (66.7-96.9\%) among 100 traditional rice accessions/varieties with a total of 387 alleles identified with an average of 11.72 alleles per accession. The AMOVA results showed that $34 \%$ of the variation distributed among accessions, $59 \%$ of among individuals and $7 \%$ within individual indicating a comparatively high level of genetic differentiation among individuals of selected rice accessions. Structure analysis results illustrated that all 100 


\section{Development of a Diversity Panel for Traditional Rice (Oryza Sativa L.) Accessions/Varieties in Sri Lanka}

accessions were genetically structured into five (05) well-separated groups, high $\Delta K$ peak was recorded at $K=15, K=5, K=19$ and $\mathrm{K}=2$ respectively (Figure 3 ).

UPGMA analysis based on Jaccard's similarity separated the accessions/varieties into five (5) major clusters (Figure 4). A cophenetic correlation with $r=0.786$ strongly supported the clustering pattern of UPGMA dendrogram. A principal coordinate analysis (PCOA) also confirmed the UPGMA clusters. Accessions/varieties referred to the same cluster showed similar morphological characteristics (e.g. flag leaf angle, lema-paleacolour etc.) while accessions which are identified as morphologically distinct appeared genetically separated.

Breeding a new variety based on phenotypic characters may take more than a decade and, even then the release of an improved variety cannot be guaranteed. Molecular markers make this procedure more efficient and expedite the selection process in rice breeding. Hence, molecular markers are widely used as an efficient tool to characterize genetic variability. A similar study was conducted by Rajkumar et al., (2011) on the genetic diversity of 46 traditional rice (Oryza sativa) varieties in Sri Lanka using Amplified Fragment Length Polymorphism (AFLP) markers with ten primer combinations. A UPGMA analysis based on Jaccard's similarity separated the accessions into four major clusters. Traditional rice accessions referred to the same cluster showed similar morphological characteristics (e.g. height, grain colour etc.) while accessions which are known to be morphologically distinct appeared genetically separated.

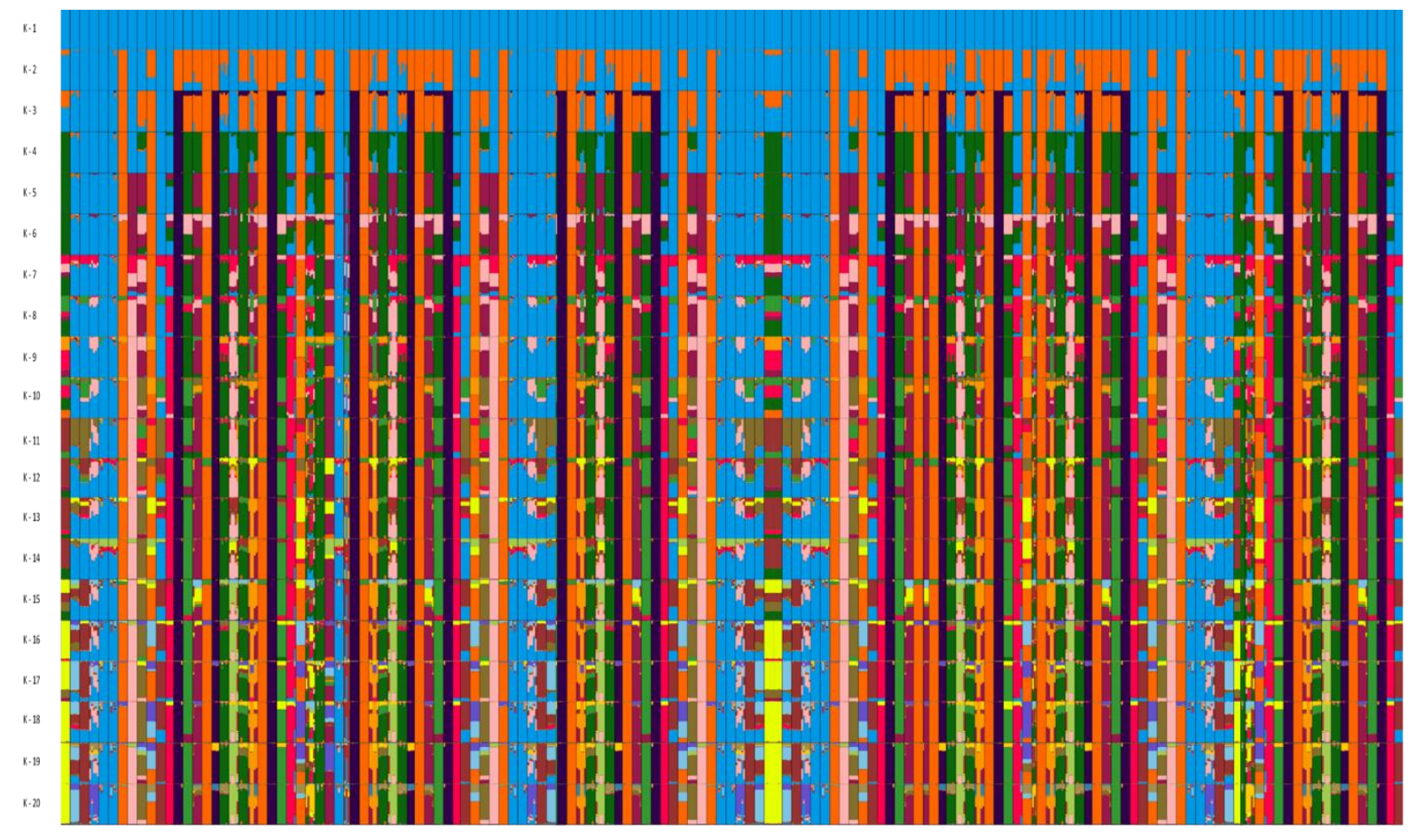

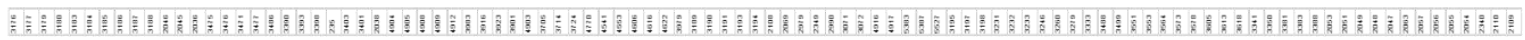

Figure 3: STRUCTURE results bimodal-based population assignment at $\mathrm{K}$ from 1 to 20. Each vertical bar represents an individual (100accessions/varieties), with its assignment probability to genetic clusters represented

By different colors 


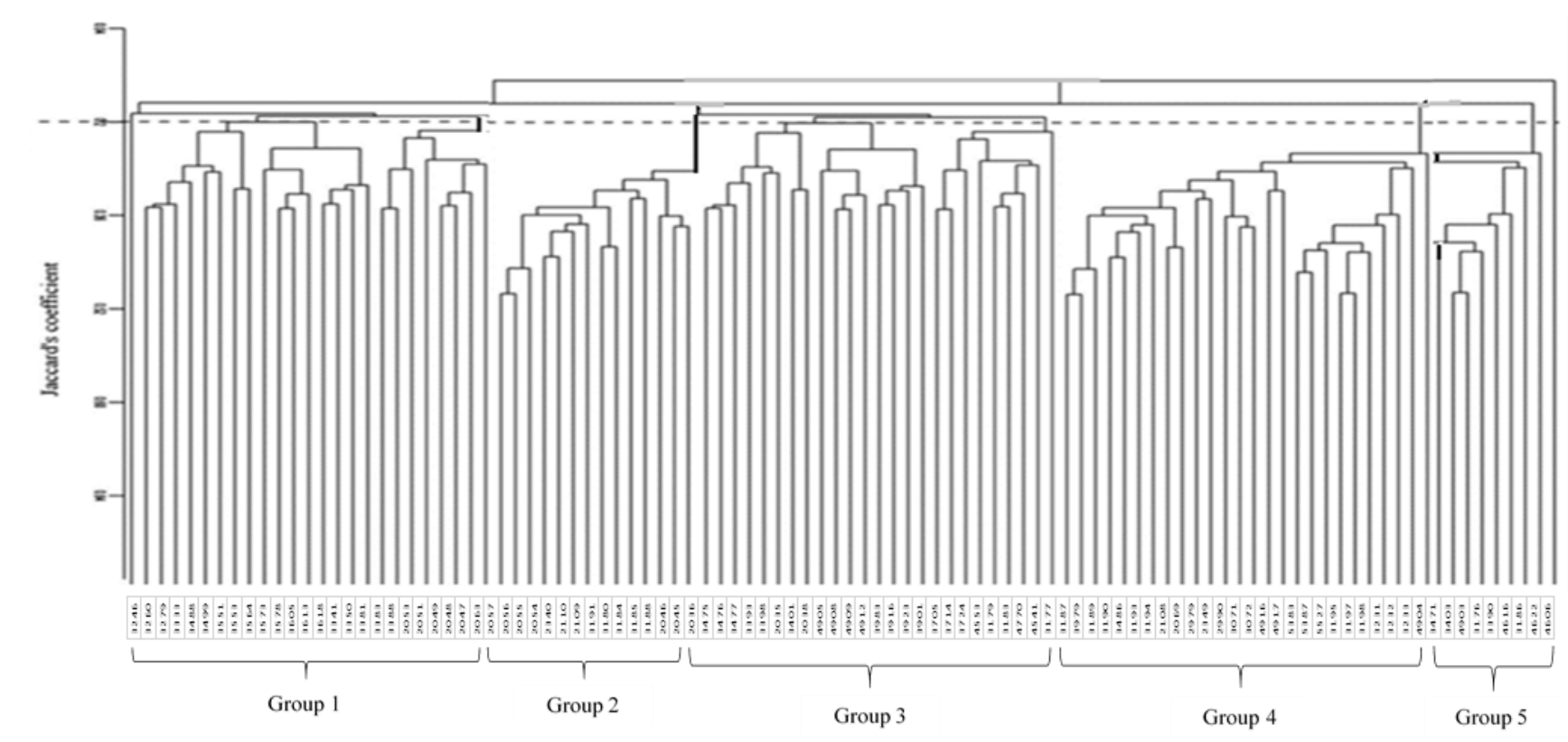

Figure 4. The UPGMA dendrogram showing genetic diversity among one hundred Sri Lankan traditional rice accessions/varieties based on Jaccard's similarity coefficient.

\section{CONCLUSIONS}

The genetic diversity observed among the traditional rice accessions/varieties is significantly high. Genetic diversity assessment at agro-morphological level provides reliable information for the selection of germplasm to develop new rice varieties and in the conservation of traditional rice genetic resources for future breeding programs. The studied 100 traditional rice accessions/varieties consist of seven (07) groups which can be characterized by the characters, lemma-palea color, presence or absence of awn, seedling height, and flag leaf angle.

However, genetic diversity assessment at the molecular level provides reliable information for selection of germplasm in the development of new rice varieties and in conservation of traditional rice genetic resources. Structure analysis and UPGMA analysis based on Jaccard's similarity separated the tested 100 rice accessions/varieties into five (5) major clusters.

All methods of analyses produced similar results confirming the reliability of data used in this study. Therefore, the genetic diversity information obtained will be useful in efficient use of Sri Lankan rice germplasm collection in breeding programmes. In addition, this information will be useful in management of in situ and exsitu germplasm collections in conservation programs for traditional rice varieties. Studies on genetic differentiation are also important to avoid duplication of traditional rice accessions/ varieties in the Gene Bank at PGRC.

\section{ACKNOWLEDGEMENTS}

Authors wish to thank Faculty of Natural Sciences Research Grant, The Open University of Sri Lanka for financial support. Technical assistance by MsKalpniWidanapathirana and MsChamodiSandanayake is gratefully acknowledged.

\section{REFERENCES}

1) Abeyratne, E.F. (1956). Dry land farming in Ceylon. 1. Tropical Agriculturalist, 112(3): 191-229.

2) Atwell, B. J., Wang, H. \&Scafaro, A. P. (2014). Could abiotic stress tolerance in wild relatives of rice be used to improve Oryza sativa? Plant Science, 215-216: 48-58.

3) Bentota, A.P. and Weerasinghe, B.G.D.S. (2005). Iron toxicity tolerance in some traditional rice varieties of Sri Lanka, Annals of the Sri Lanka Department of Agriculture, Department of Agriculture, Peradeniya, Sri Lanka. 7:337-340. Brekenridge, C. (1980).

4) Camacho Villa, T.C.,Maxted, N., Scholten, M., Ford-Lloyd, B. (2005) Defining and identifying crop landraces, Plant Genetic Resources; Characterisation and Evaluation, Vol. 3, no. 3, pp. 373-384, 2005.

5) Cho YG, Ishii T, Temnykh S, Chen X, Lipovich L, McCouch SR, Park WD, Ayres N, Cartinhour S (2000). Diversity of microsatellites derived from genomic libraries and GeneBank sequences in rice (Oryza sativa L.). Theor Appl Genet 100:713-722.

6) Crop Recommendations (2014). Department of Agriculture, Sri Lanka. 


\section{Development of a Diversity Panel for Traditional Rice (Oryza Sativa L.) Accessions/Varieties in Sri Lanka}

7) Choudhury, B., Khan, M.L. \& Dayanandan, S. (2013). Genetic structure and diversity of indigenous rice (Oryza sativa) varieties in the Eastern Himalayan region of Northeast India. SpringerPlus, 2(1), p.228.

8) Efisue A., Tongoona P., Derera J., Langyintuo A., Laing 8. M. \& Ubi B. (2008). Farmers' perceptions on rice varieties in Sikasso region of Mali and their implications for rice breeding. Journal of Agronomy and Crop Science, 194(5): 393-400.

9) Kobayashi, N., Ikeda, R., Vaughan, D. A.\& Shigenaga, S. (1991) Resistance to tungro in some wild relatives of rice. International Rice Research Newsletter 16 (4): 13.

10) Lin C.S. \& Binns M.R. (1985). Procedural approach 12. for assessing cultivar-location data: pair wise genotypeenvironment interactions of test cultivars with checks. Canadian Journal of Plant Science, 65(4):1065-1071.

11) Lin C.S., Binns M.R. \& Lefkovitch L.P. (1986). 13. Stability analysis: where do we stand? Crop Science, 26(5): 894-900.

12) Mandal A.B., Pramanik S.C., Chowdhury B. \& 14. Bandyopadhyay A.K. (1999). Salt-tolerant Pokkalisomaclones : performance under normal and saline soils in Bay Islands. Field Crops Research, 61(1): 13-21.

13) Madurangi, S. A. P., Ranawake, A. L.\& Dahanayake, N. (2012). Evaluation of level of drought tolerance in traditional rice cultivars in Sri Lanka at the seedling stage. Proceedings of the International Symposium on Agriculture and Environment 2012, Ruhuna, Sri Lanka, 29 November, 2012. pp.325-327.

14) Munasinghe, S. P. Somaratne, S. and Weerakoon, S. R. (2017). Screening of Sri Lankan Rice (Oryza sativa L.) Landraces for Drought tolerance. Tropical Agricultural Research, 28 (2), 183-191.

15) Panabokke C.R. (1996). 15. Soils and Agro-ecological Environments of Sri Lanka. Natural Resources Series - 2 , pp 31. Natural Resources and Energy Authority, 47/5, Maitland Place, Colombo 7.

16) PGRC Characterization Catalogue on Rice Germplasm (1999). Plant Genetics Resource Center (PGRC), Gannoruwa, Sri Lanka.

17) Ranawake, A. L. \& Amarasinghe, U. G. S. (2014). Relationship of Yield and Yield Related Traits of Some Traditional Rice Cultivars in Sri Lanka as Described by Correlation Analysis. Journal of Scientific Research and Reports, 3 (18): $2395-2403$. https://doi.org/10.9734/JSRR/2014/12050

18) Rajkumar, G., Weerasena, J., Fernando, K., Liyanage, A. \& Silva, R. (2011). Genetic differentiation among Sri Lankan traditional rice (Oryza sativa) varieties and wild rice species by AFLP markers. NORDIC Journal of Botany, https://doi.org/10.1111/j.1756-1051.2011.00998.x

19) Ren F, Lu BR, Li S, Huang J, and Zhu Y, (2005). A comparative study of genetic relationships among the AA-genome Oryza species using RAPD and SSR markers. TAG Theoretical and Applied Genetics, vol. 108, no. 1, p. 113-120.

20) Roa AC, Chavarriaga-Aguirre P, Duque MC, Maya MM, Bonierbale MW, Iglesias C, Tohme J (2000). Cross-species amplification of Cassava (Manihot esculenta) (Euphorbicaceae) microsatellites: allelic polymorphism and degree of relationship. Am J Bot 87:1647-1655.

21) Samita S., Anputhas M. \& Abeysiriwardena D.S. de Z. 18. (2005). Accounting for multi traits in recommending rice varieties for diverse environments. Experimental Agriculture, 41(2): 213-225.

22) Shishido, R.; Kikuchi, M.; Nomura, K. and Ikehashi, H. (2006). Evaluation of genetic diversity of wild rice (Oryza rufipogon Griff.) in Myanmar using simple sequence repeats (SSRs). Genetic Resources and Crop Evolution, vol. 53, no. 1, p. $179-186$.

23) Thomson M., Septiningsih E., Suwardjo F., Santoso T., 26. Silitonga T. \& McCouch S. (2007). Genetic diversity analysis of traditional and improved Indonesian rice (Oryza sativa L.) germplasm using microsatellite markers. TAG Theoretical and Applied Genetics, 114(3): 559-568.

24) Yu SB, Xu WJ, Vijayakumar CHM, Ali J, Fu BY, Xu JL, Jiang YZ, Marghirang R, Domingo J, Aqino C, Virmani SS, and Li ZK (2003). Molecular diversity and multilocus organization of the parental lines used in the International Rice Molecular Breeding Program. TAG Theoretical and Applied Genetics, vol. 108, no. 1, p. 131-140.

25) Wickramasinghe H.A.M. \& Noda T. (2008). 27. Physicochemical properties of starches from Sri Lankan rice varieties. Food Science and Technology Research, 14(1): 49-54. 